\title{
The Health Benefits of Exercise and Physical Activity
}

\author{
Keith R. Miller ${ }^{1}$ - Stephen A. McClave ${ }^{2}$ - Melina B. Jampolis ${ }^{3} \cdot$ Ryan T. Hurt $^{4}$ • \\ Kristine Krueger $^{2} \cdot$ Sarah Landes $^{2} \cdot$ Bryan Collier $^{5}$
}

Published online: 14 July 2016

(C) Springer Science+Business Media New York 2016

\begin{abstract}
Physical inactivity is a modifiable risk factor (similar to dyslipidemia and hypertension) for a variety of chronic diseases, including cancer and cardiovascular disease. Exercise provides a clear health benefit, which serves in the primary and secondary prevention of these disease processes (the most important being a reduction in cardiovascular disease and premature death). The physiologic mechanisms for such a benefit occur at both a cellular and multisystem level. Prolonged periods of occupational or leisure-time sitting have adverse health effects independent of exercise performed before or after. Almost any form of physical activity (PA) is beneficial, whether part of a regular exercise program or as a series of intermittent, incidental, non-purposeful, lifestyleembedded activity (causing non-exercise activity thermogenesis or NEAT). The health benefits of exercise appear to be dose-dependent. Physicians should recommend near daily exercise which includes at various times strength training, stretching, and aerobic activity in addition to emphasizing
\end{abstract}

This article is part of the Topical Collection on Gastroenterology, Critical Care, and Lifestyle Medicine

Keith R. Miller

krmill10@louisville.edu

1 Department of Surgery, University of Louisville School of Medicine, Louisville, KY 40202, USA

2 Department of Medicine, University of Louisville School of Medicine, Louisville, KY, USA

3 National Board of Physician Nutrition Specialists, Valley Village, CA 91607, USA

4 Department of Medicine, Mayo Clinic, Rochester, MN, USA

5 Department of Surgery, East Virginia University, Roanoke, VA, USA adjustments that allow for reduced sitting and increased activity during daily routines. Patients should understand that for optimal health, exercise is no longer optional.

Keywords Exercise $\cdot$ Physical activity $\cdot$ Inactivity $\cdot$ Energy expenditure $\cdot$ Non-exercise activity thermogenesis

\section{Introduction}

Physical inactivity is a modifiable risk factor for cardiovascular disease, obesity, depression, cancer, diabetes mellitus, hypertension, and osteoporosis. Physical exercise reduces the risk of premature death and prolongs longevity, and is an important treatment modality in the primary and secondary prevention of the above disorders [1]. For most states in this country, less than half of the population meets CDC exercise recommendations [2•]. The decline in physical activity (PA) occurs both at work and in leisure time, and may have at least partially contributed to the increase in obesity over the past 30 years. Low recreational physical activities have been associated with a threefold increase for major weight gain in men and a fourfold increase in women [3]. Surveys of PA across the lifecycle show that physical exercise peaks in the middle high-school age range and begins declining through high school and into adult life. A vicious cycle of decline occurs between inactivity and loss of skeletal muscle mass which accelerates with age. With avoidance of activity requiring effort, there is increased loss of exercise capacity. This loss causes the perception of effort associated with even submaximal work to worsen, as the anaerobic threshold decreases. The vicious cycle contributes to further inactivity and deterioration of physical function. The only treatment that can break the cycle is exercise. 


\section{Impact of Exercise on Aging}

Exercise provides powerful health benefits for quality of life, physical function, and independent living throughout the life cycle. Exercise impedes the aging process and promotes longevity. Observational studies have shown that even in the presence of disease processes such as hypertension (HTN), chronic obstructive pulmonary disease (COPD), diabetes, smoking, high body mass index (BMI), and hypercholesterolemia, increasing PA has a dose-dependent effect in decreasing relative risk of death [4]. In a study of subjects over a 13-year time period, both baseline fitness, and improvement in physical fitness through exercise and PA was associated with significant increases in longevity [4]. Functional independence with advanced age relates to the overall level of physical fitness. Physical fitness is most affected by the status of the cardiorespiratory and vascular systems, as well as muscle function $[5 \cdot]$.

Garatachea et al. provide an excellent review of the effect of exercise on the physiologic changes associated with aging [5•]. Exercise exerts its positive influence on both a cellular level and at the level of organ systems. At the cellular level, exercise helps reduce genomic instability, epigenetic alteration, loss of proteostasis, dysregulated nutrient sensing, cellular senescence, and altered intracellular communication that leads to inflammation. These effects alter the way the body performs transcellular signaling in the skeletal muscle, the turning on and off of genes through epigenetics, and the manner in which the system manages reactive oxygen species [5•]. On a multisystem level, the benefits of exercise include improvement in brain, cardiovascular, lung, and muscle function, favorable alterations in body composition, and advantageous changes in metabolic responses. The report concludes by suggesting that in the future, pharmaceuticals should be designed which mimic the effects of exercise on the aging process $[5 \bullet$.

\section{Effect of Exercise on Treatment of Disease}

Robert Butler from the National Institute on Aging has said that "If exercise could be put in a bottle, it would be the strongest medicine money could buy" [6]. Exercise helps prevent common chronic diseases (primary prevention), and often plays an important role in the treatment of these disease processes (secondary prevention). Specific benefits from exercise have been seen with cardiovascular disease, stroke, diabetes mellitus, depression, cancer, obesity, and osteoporosis $[7,8]$

\section{Cardiovascular Disease}

Increased levels of PA and physical fitness have a graded effect in reducing the risk of death from cardiovascular disease. The relative risk from all cause and cardiovascular disease mortality is reduced $20-35 \%$ by exercise and PA [9]. In an observational study, subjects in the lowest quintile of exercise had a relative risk of 3.4 in men and 4.7 in women for death compared to those in the highest quintile [10]. An increase in activity-related energy expenditure by as little as $1000 \mathrm{kcal}$ or 1 metabolic equivalent (MET)-hour of exercise per week has a mortality benefit of $20 \%$ [11]. Physically inactive women have a $52 \%$ increase in death, a cardiovascular disease-related death that is doubled, and a cancerrelated death rate that is increased by $29 \%$ [11]. These risks on mortality from inactivity are similar to other modifiable risk factors such as HTN, hypercholesterolemia, and obesity. In randomized controlled trials (RCT)s, exercise and PA are valuable for the secondary prevention of cardiovascular disease. Whereas in the past, traditional recommendations for patients with a heart attack included rest and physical inactivity. Newer information demonstrates that exercise actually attenuates or reverses risk of cardiovascular disease [12]. The benefit of exercise is seen in cardiac rehabilitation, where increasing PA reduces the risk of premature death following a myocardial infarction [12]. Added energy expenditure of $1600 \mathrm{kcal} /$ week from exercise may halt the progression of heart disease and energy expenditure of $>2200 \mathrm{kcal} / \mathrm{week}$ can lead to plaque reduction [13]. The minimum training recommendation for patients following myocardial infarction is to reach $45 \%$ of their heart rate reserve through cardiac rehabilitation $[12,13]$.

Multiple mechanisms have been identified whereby exercise reduces the risk of premature death [4]. Exercise affects body composition by decreasing abdominal adiposity and improving weight control. Exercise enhances lipid profiles by reducing serum triglyceride levels, raising HDL, and reducing the LDL/HDL ratio. In addition, a recent meta-analysis showed beneficial changes in lipoprotein subclasses associated with regular exercise including a reduction in small LDL-p and an increase in large LDL-p [14]. Exercise enhances hemodynamics by decreasing blood pressure, increasing cardiac function, and improving coronary blood flow. Autonomic tone is enhanced and shear stress-mediated endothelial function is improved. Exercise reduces systemic inflammation, as evidenced by reduced C-reactive protein (CRP) levels. Improved psychological well-being in response to exercise is associated with reduced stress, anxiety, and depression [4].

\section{Stroke}

PA is inversely correlated with risk of incident stroke as shown in a large nurses' health study [15]. Habitual exercise reduces risk of stroke by $40-50 \%$ at the highest level of PA. Change in PA is protective against stroke as evidenced by the fact that an increase of $3.5 \mathrm{~h}$ of exercise or PA per week is associated with a $29 \%$ reduction in ischemic stroke [15]. 


\section{Diabetes Mellitus}

Exercise is valuable in both the primary and secondary prevention of diabetes mellitus. Aerobic and resistant-type exercise reduces the likelihood of developing type-2 diabetes mellitus. For each $500 \mathrm{kcal}$ of energy expended per week, there is an associated $6 \%$ reduction in the likelihood of type-2 diabetes (which may be even greater with increasing BMI) [16]. In patients already diagnosed to have diabetes mellitus, walking $2 \mathrm{~h}$ per week is associated with a $39-54 \%$ reduction in all-cause mortality from diabetes mellitus, and a $34-53 \%$ reduction in mortality related to cardiovascular disease [17]. The benefit of exercise on glycemic control appears to be greater with resistance training than aerobic exercise. A meta-analysis of exercise and PA in diabetes showed that exercise reduces hemoglobin $\mathrm{A} 1 \mathrm{C}$ by $0.66 \%$, an effect similar to intensive glucose-lowering pharmacologic therapy [18]. The mechanisms by which exercise benefits diabetes relate to the fact that exercise increases glycogen synthetase and hexokinase activity [4]. Exercise reduces GLUT-4 protein and messenger RNA expression and increases muscle capillary density, which helps improve glucose delivery to the muscle [4].

\section{Cancer}

Increasing PA, either occupational or at leisure, has been shown to exert a primary preventative effect on two cancers-breast and colon cancer [19]. Moderate exercise of as little as 4-5 METs (equivalent to mowing the lawn or brisk walking), is required to achieve this effect [20]. Exercise is associated with a $20-30 \%$ reduction in the incidence of breast cancer in women, and a 30-40 \% reduction in the incidence of colon cancer in both men and women [20]. In those patients already diagnosed to have one of these cancers, exercise reduces the likelihood for cancer recurrence and reduces risk from cancer death by as much as $26-40 \%$ [21]. PA improves quality of life and overall health status in cancer patients. The mechanisms by which exercise improves risk from cancer may relate to reduced fat stores, an increase in energy expenditure offsetting a high-fat diet, activity-related changes in sex hormone levels, improvement in immune function, and reduced generation of free oxygen radicals [4].

\section{Osteoporosis}

Exercise has a valuable effect in the primary prevention of osteoporosis. Routine PA minimizes age-related bone loss. Weight-bearing exercise (especially resistance exercise) increases bone density compared to low impact non-weightbearing exercise. Exercise prevents $1 \%$ of bone loss per year, an effect which is greater in post-menopausal than premenopausal women [22]. In RCTs, exercise reduces the risk and number of falls, as well as the risk of fracture [22]. Even in men, PA reduces the risk of fracture by $62 \%$ over the age of 21 years [23]. Exercise is also valuable in the secondary prevention of osteoporosis. RCTs in the past have shown that exercise with resistance training increases bone density in older osteoporotic women by as much as $1.4 \%$, while agility training alone increases bone density by $0.5 \%$ [24]. Stretching, which was used as sham control, was shown to have no effect on the expected decrease in bone density with age [24]. In a 12-year follow up of over 60,000 postmenopausal women, risk of hip fracture was lowered $6 \%$ for each increase of three MET-hours per week of activity (the equivalent of walking three miles in $1 \mathrm{~h}$ ) [25]. Active women with at least 24 met-hours of exercise per week had a $55 \%$ lower risk of hip fracture than sedentary women with no other exercise. Walking at least $4 \mathrm{~h}$ per week was associated with a $41 \%$ lower risk of hip fracture than walking less than one hour per week [25].

\section{Depression}

Exercise has a valuable therapeutic effect on the treatment on multiple types of depression, including dysthymic, seasonal, bipolar, post-natal, pre-menstrual, atypical, and major depression [26]. The value in treating depression comes from an innate anti-depressive effect from exercise. Combining exercise with psychotropic medications achieves better treatment results than the same medications alone [26]. Exercise is relatively inexpensive, safe, and has minimal side effects when done correctly. Exercise may help reduce the dose of antidepressive medications required. Subjects are less likely to relapse with an active exercise program [26].

The patients with depression who are most likely to benefit from exercise include those with age $<20$ or $>40$ years, higher education, higher baseline physical status, females, untrained subjects, and those with mild to moderate depression [26]. There are a number of aspects of exercise that get the optimal results in treating depression including programs that are structured, individually tailored to the patient, low to moderate intensity, when it is used as an adjunct to medication therapy, and exercise that is a combination of aerobic or resistive training performed 3-4 times per week [26]. The mechanism of effect from exercise on depression occurs on a systemic level as well as a direct effect on central nervous system (CNS) function. Exercise appears to increase serotonin, ACTH, endorphins, and endocannabinoids within the CNS. On a systemic level, exercise increases norepinephrine and reduces cortisol, tumor necrosis factor (TNF), and interleukin-6 [26].

\section{Obesity}

In a controversial article that appeared in Time magazine in 2009, the journalist John Cloud wrote about "The Myth of 
Exercise" and its effect on treating obesity [27]. The article suggested that exercise was not good for weight management in obesity. The author pointed out that exercise leads to increased appetite and intake of food and causes a decrease in non-exercise energy expenditure, and therefore that exercise was a poor strategy for weight loss [27]. A number of letters to the editor of Time magazine followed the publication of this article, including letters from the American Society for Sports Medicine, arguing that facts were misrepresented and that the article gave the wrong message about the health benefits of exercise.

A recent review by Swift clarified the role of exercise in managing or preventing obesity, and suggested that Cloud's article was in fact an accurate portrayal of the facts [28]. The key issue of Swift's review is that exercise without caloric restriction is unlikely to succeed in weight loss [28]. Increasing PA can prevent weight gain, but it requires 150-250 min per week of moderate to vigorous exercise or 1200-2000 kcal/week expended through exercise to accomplish this feat [29]. Aerobic exercise by itself is minimally helpful in promoting weight loss, successful in loss of only $0-2 \mathrm{~kg}$ total [29]. Extreme high-volume aerobic exercise can achieve significant weight loss, but this is usually unsustainable by most obese patients. Moderate intensity, surprisingly, is no different than vigorous intensity in achieving weight loss, unless subjects are matched for exercise duration. Resistance training by itself has no impact on weight loss, and aerobic training combined with resistant training has no greater effect than aerobic training alone. However, adding caloric restriction to aerobic training does result in successful weight loss of 9-13 kg, and higher intensity of exercise has the potential for even greater weight loss [29]. Some obese subjects do experience weight compensation in response to exercise, defined by the circumstances where less weight is lost than expected with the amount of exercise sustained, often a factor related to an increase in caloric intake $[28,30]$. This is more likely to occur in women performing $150 \%$ of weekly recommendations (compared to women performing only $100 \%$ or $50 \%$ of weekly recommendations) $[28,30]$. Even if minimal or no weight loss occurs in response to exercise, obese subjects still benefit from the increase in PA due to increased cardiorespiratory fitness, glucose control, endothelial function, improvements in hyperlipidemia, quality of life, and a reduction in future weight gain [28].

Caloric restriction is better than exercise for significant weight loss initially, and the weight loss is not necessarily enhanced significantly by adding exercise [28], although exercise training plus caloric restriction does improve body composition by increasing fat loss and decreasing loss of lean body mass [31]. The greatest value of exercise in the management of obesity occurs not in the initial weight loss, but in the situation where obese patients have lost weight successfully and now require substantial PA to maintain that weight loss [28]. Interestingly, an "energy gap" has been identified as the difference in energy expenditure before and after weight loss [32]. The energy gap is estimated to be approximately $8 \mathrm{kcal}$ per day per pound of weight lost. An energy gap, for example, of $40 \mathrm{lbs}$ lost would be associated with $320 \mathrm{kcal}$ of energy. Sustaining this weight loss successfully would require either a continued reduction in energy consumption by $320 \mathrm{kcal}$ per day, or increasing activity-associated energy expenditure by the same amount [32]. Based on the Set Point theory, both biological and environmental pressures oppose the strategy of food restriction in keeping weight off, but the same effect does not occur with increased PA [32]. Therefore, while food restriction is the key to weight loss, PA is the key to successful maintenance of the weight lost [32]. The ACSM has identified that people who successfully maintain weight loss average at least 250 min of PA per week [29].

\section{Low Back Pain}

A 2016 systematic review and meta-analysis reviewed 23 randomized controlled trials evaluating the prevention of low back pain [33]. Over 30,000 patients were involved in these studies. Ultimately, the combination of exercise (varying regimens of abdominal strengthening, core stability, cardiovascular, and isometrics) plus education regarding prevention of low back pain was found to reduce the risk of low back pain as well as sick leave related to low back pain. Exercise alone was also found to have an impact but had a more short term effect ( $<12$ months), thought to be due to cessation of exercise following the intervention. Other interventions, including back belts, insoles, and education alone were not found to have any impact [33].

\section{Not All Exercise is Created Equal}

\section{Physical Activity Versus Physical Fitness}

The lay public tends to use the terms PA and physical fitness interchangeably, but subtle differences between the two exist. Physical fitness is a physiologic state of being with regard to daily living and/or sports performance [4]. Physical fitness is comprised of cardiovascular, musculoskeletal, body composition, and metabolic components [4]. Physical fitness is similar to PA, but is more predictive of health outcomes. For example, a high-fit versus a low-fit person is estimated to have a $50 \%$ lower mortality [34]. Physical fitness, therefore, becomes a better measure of PA than self-reporting. From a public health standpoint, however, it is better and more productive to encourage the public to be physically active and not push the need to be physically fit. Eventually, increased activity should lead to physical fitness. 
In the past, guidelines for optimal health seemed to have had a singular focus on aerobic fitness. But a new paradigm shift has occurred with the addition of the concept of musculoskeletal fitness [4]. In other words, health status can improve due to increased PA in the absence of changes in aerobic fitness. Regular PA can decrease risk factors from chronic disease and disability without changing cardiac output or oxidative potential, especially in the elderly [4]. The shift has been to focus on the health benefits of musculoskeletal fitness, which may be a critical factor in the functional threshold for dependence with the aging population. Loss of muscular fitness can result in loss of capacity for daily living, and a cycle of decline can ensue [4]. Improvement in musculoskeletal function can delay the onset of disability, dependence, and chronic disease [35]. Musculoskeletal fitness is associated with fewer functional limitations and a reduced incidence of cardiovascular disease, diabetes, degenerative joint disease, and coronary artery disease [35]. Therefore, resistance training that works all the major muscle groups (including legs, hips, back, abdomen, chest, shoulders, and arms) and flexibility exercise, which are necessary to achieve musculoskeletal fitness, are recommended to be done at least twice weekly, to complement aerobic fitness and optimize overall health status.

\section{Adverse Health Risk from Sitting}

In an effort to delineate those factors which contribute to the obesity epidemic, researchers are increasingly focused on the adverse health risk from prolonged sitting [36•]. A newly recognized occupational hazard has evolved because of workers needing to sit at a computer screen throughout the workday. Each mean hour of sitting after a total mean of $7 \mathrm{~h}$ per day is associated with a $5 \%$ increase in premature death [36•]. More time sitting at work has been shown to correlate with more sitting in leisure time. Prolonged sitting while watching TV at home, for example, has adverse effects on mental health, wellbeing, and muscle strength. Long sedentary hours have been linked to a twofold increase in diabetes, a twofold increase in cardiovascular disease, a $13 \%$ increase in the incidence of cancer, and a $17 \%$ increase in mortality related to cancer [36•]. It is estimated that the average worker in the USA and England spends $60-70 \%$ of waking hours in a sedentary sitting position. The effect of sitting has been likened to the transmission of a car. Sitting for such a prolonged period is like putting a car in reverse, causing one's overall health status to go in the wrong direction [36•]. Approximately $20-30 \%$ of the time is spent in light intensity activity, described as postural changes, standing and movement, or ambulation. For less than $5-10 \%$ of waking hours, individuals spend in moderate to vigorous PA. The adverse effect of sitting on health status is independent of the exercise or PA done before or after [36•]. In other words, no amount of PA later can overcome the negative health effects of prolonged sitting.
Changes in the workplace environment may be the key issue to minimizing the negative effects of prolonged sitting. Particularly, in the UK, recommendations and guidelines have been developed to avoid this health hazard [36॰]. Workers are encouraged to accumulate up to $2 \mathrm{~h}$ per day at work standing or performing light walking, with the goal to progress ultimately to $4 \mathrm{~h}$ per day. Workers should interrupt seat-based work with standing-based work. However, workers should avoid both prolonged periods of standing as well as prolonged periods of sitting. Adaptation of these guidelines may lead to musculoskeletal complaints and fatigue, which should be monitored by managers in the workplace. Such health promotion strategies should eventually extend from the workplace to the leisure time [36•].

\section{Non-Exercise Activity Thermogenesis}

Non-exercise activity thermogenesis (NEAT) has been described as unstructured PA, energy expended unrelated to sleeping, eating, or sports exercise. NEAT is energy expended outside of purposeful exercise [37]. Surprisingly, this incidental, non-purposeful lifestyle-embedded PA can have tremendous health benefits. Three components of NEAT include body posture, ambulation, and all other movements (the most important of which may be fidgeting) [38]. Researchers involved in the study of obesity are finding that in some cases what delineates the lean subject from an obese one is a difference in NEAT, not exercise-associated activity thermogenesis [38]. Early experiments which helped identify NEAT came from studies where energy requirements were measured and all subjects were placed on a diet of $1000 \mathrm{cal}$ over requirements [39]. Subjects were then videotaped, and in a blinded fashion designated as fidgeters or non-fidgeters. At the end of the trial, those patients who were designated as fidgeters failed to gain weight, while those identified to be non-fidgeters sustained significant weight gain. The increase in kilocalories of energy expenditure attributed to NEAT was inversely proportional to fat gain in pounds [39]. NEAT ranges from $15 \%$ of total energy expenditure (TEE) in sedentary subjects to as much as $50 \%$ of TEE in fidgeting physically active people [39]. Fidgeting has been shown in twin studies to be genetic, with an estimated $>62 \%$ heritability [40]. Simply standing or lightly ambulating can increase energy expenditure by an average of $350 \mathrm{kcal} /$ day (range 269-477 kcal/day) [37]. NEAT tends to be greater in men than women, in obese subjects rather than lean, and in those with more education than those with less [38, 39]. NEAT tends to be seasonal and overall, declines with age [39]. The concept of an energy gap is pertinent to NEAT. An average citizen in the USA has been shown to gain 1-2 lbs each year through their adult life. An energy gap of $100 \mathrm{kcal}$ additional energy consumed each day would account for this weight gain [41]. NEAT can be an important contributor to TEE, such that increases in NEAT of as little as 
100-150 kcal of activity per day could prevent such weight gain (by offsetting the energy gap) in the vast majority of people [41]. Recommendations now suggest that if you were not lucky enough to inherit fidgeting, you should "act like a fidgeter," standing often, getting up from sitting, pacing, parking at the back of a parking lot, and taking stairs instead of elevators [40].

\section{Continuous Versus Interval Exercise}

Long bouts of continuous exercise as a strategy for weight loss or weight maintenance can be a contentious and challenging recommendation for the general public. Longer duration, continuous exercise may be difficult and not particularly enjoyable for patients and may not fit as well with work or home schedules. Research now has shown that interval exercise, which involves alternating short bouts of high-intensity exercise with lower-intensity exercise that allows for partial recovery, can match the health benefits of continuous exercise [42]. Studies in patients with class-1 obesity (BMI $30-34.9 \mathrm{~kg} / \mathrm{m}^{2}$ ), walking at a moderate level of intensity, randomized to two 15-min intervals of walking versus one 30-min interval, showed essentially the same improvements in overall health status [42]. Both intermittent and continuous exercise resulted in improvement of maximum oxygen consumption, body composition, and lipid profiles. In some categories, interval exercise even exceeded the benefit seen with continuous exercise (such as VLDL levels and percent fat lost) [42]. The value of these findings for intermittent exercise stems from three factors: there is less attrition with recommendations for interval exercise, time constraints, and short periods of interval exercising may allow for greater intensity of PA [42]. An additional study involving 28 sedentary overweight or obese men compared five 45 - to 60 -min sessions of continuous moderate intensity cycling per week for 6 weeks with three 20-min sessions of high-intensity interval exercise per week (for a total of $60 \mathrm{~min}$ ) for 6 weeks. Similar improvements in cardio-metabolic risk factors including improved insulin sensitivity, cardiovascular fitness, and a reduction in blood lipids and body fat percentage were observed in the groups [43]. While cardiovascular fitness was improved to a greater extent in the continuous exercise group, this study, along with numerous other studies of interval exercise showing similar outcomes in different populations, are encouraging in that they show many of the same improvements in overall health with a substantially reduced time commitment [43]. This is especially relevant as lack of time is cited as the most common reason for not exercising by many. In addition, interval exercise can be easily adapted to an individual's starting fitness level by adjusting either the duration or intensity (or both) of the highintensity component of exercise. This may be especially beneficial for sedentary overweight or obese individuals who are new to exercise. In light of both the potential health and time saving benefits, interval exercise training appears to be an appealing and worthwhile exercise option in addition to, or instead of, continuous exercise. The good news for public health is that short walks on a subject's lunch break or brief periods of activity before and after work all count, and the sum of their duration may have similar benefits to a single continuous interval of exercise of the same duration.

\section{Success of Pedometers}

The use of pedometers to increase PA was generated years ago in Japanese walking clubs. The rationalization for the pedometer was that the average stride was estimated to be $2.5 \mathrm{ft}$. Therefore, 2000 steps should approximately equal a mile, 10,000 equaling about 5 miles [44]. Based on this rationalization, PA can be classified as sedentary ( $<5000$ steps per day), low active (5000 to 7500 steps), somewhat active (7500 to 10,000 steps), and active ( $>10,000$ steps per day). Highly active physical exercise is associated with $>12,500$ steps per day [44]. This is an arbitrary categorization, however, and 10,000 steps per day may be too little for children or too much for the elderly. Weight loss using a pedometer without caloric restriction is associated with minimal to modest weight loss of $<2 \mathrm{~kg}$ [44]. Health benefits associated with use of the pedometer may be limited to a reduction in blood pressure, with not much change in cholesterol, triglycerides, or fasting glucose [44].

\section{Exercise in the Intensive Care Unit}

Exercise is becoming increasingly important in one of the least expected circumstances, that of a critically ill patient in the intensive care unit (ICU). Researchers have found that exercising muscle increases the uptake of amino acid fuel and promotes greater protein synthesis [45, 46]. Patients in the ICU on a ventilator in some centers are gotten out of bed and encouraged to walk with assistance in the hallway. Other centers have used a pedaling device, some of which can even be adapted for passive activity in a patient who is otherwise sedated and minimally responsive. Exercise in the critical care setting helps maintain muscular strength, reduces the risk for long-term neuromuscular weakness, shortens rehabilitation, and is more likely to result in the patient being discharged to their home $[45,46]$.

\section{Recommendations for Public Health}

Similar to the Food Guide Pyramid designed by the USDA, an activity pyramid has been created to guide the public in strategies to increase flexibility, muscular strength, and aerobic capacity (www.wellspan.org/media/3648/activitypyramid2009.pdf). Every day, subjects are encouraged to increase 
activity in leisure and at work. Three to five times per week, aerobic activity should occur, accumulating $150 \mathrm{~min}$ each week (www.wellspan.org/media/3648/activitypyramid-2009. pdf). Two to three times per week, muscular activity focusing on flexibility and strength training should be scheduled. Sitting more than $30 \mathrm{~min}$ at a time, watching TV, or staring at a computer screen should be minimized or reduced as much as possible (www.wellspan.org/media/3648/ activitypyramid-2009.pdf).

Guidelines differentiate between moderate and vigorous intensity of PA. Moderate intensity is defined by a 3-5 MET level of effort, and includes activities that cause some increase in breathing and heart rate (such as walking 3-4 miles per hour, bicycling on level ground, light swimming, gardening, or mowing a lawn) [4]. Vigorous intensity is defined by $\geq 6$ METs, and is exemplified by activities causing large increases in breathing, heart rate, and sweating. Such activities of vigorous intensity would include jogging or running at faster than a 10 min mile, aerobic dancing, competitive sports, heavy yard or construction work, brisk swimming, or fast bicycling [4].

The amount of PA needed to optimize health is not clear. The particular dose of exercise required to achieve benefits with regard to a particular disease process is difficult to ascertain. For cardiovascular disease, the intensity of PA is inversely and linearly associated with increased mortality, with the biggest effect seen as a reduction of premature death [47]. PA of $>2000 \mathrm{kcal}$ per week extends life by $1-$ 2 years by age 80 [47]. An average energy expenditure of $1000 \mathrm{kcal}$ per week is associated with a $20-30 \%$ decrease in all-cause mortality. Beginning at a minimum of $1000 \mathrm{kcal}$ per week, increasing benefits are seen with increasing energy expenditure, suggesting a dose-response gradient to the effect of exercise on cardiovascular health [47]. For diabetes mellitus, there is decreased risk from this disease process with PA of $>5.5$ METs for at least $40 \mathrm{~min}$ per week [48]. Walking $2 \mathrm{~h}$ per week decreases the risk of premature death from diabetes [48]. Moderate exercise defined by a $>4.5$ METs for 30-60 min per day reduces both the risk of colon cancer and breast cancer [19]. For women in particular, $>7 \mathrm{~h}$ per week of moderate exercise has been shown to be successful in reducing risk of breast cancer (TI01). For osteoporosis, the dose-response gradient is less clear, with recommendations simply emphasizing that osteogenic adaptation is load-dependent and site-specific [4]. The Center for Disease Control (CDC), the American College of Sports Medicine, and the Healthy People 2010 recommendations provide guidelines for aerobic activity for public health purposes [49]. Adults should engage in PA of moderate intensity for at least 150 min per week or engage in PA of vigorous intensity for at least $75 \mathrm{~min}$ per week. Bouts of exercise may be broken up into smaller increments lasting at least $10 \mathrm{~min}$ [49].

\section{Should Anyone Not be Exercising?}

Jim Fixx was a celebrity journalist who helped contribute to the running craze seen in the 1980s in the USA. His sudden death from cardiovascular disease, while jogging, raised questions as to the need for medical evaluation prior to engaging in a program of increasing PA. Moderately strenuous PA may trigger ischemic events, particularly among sedentary people. There is an increased incidence of primary heart attack in high-intensity exercise. In competitive athletes, $80 \%$ of deaths are caused by coronary artery disease. Some subjects do need to have their health risks assessed prior to engaging in an aggressive program.

The degree to which a person is evaluated prior to exercise depends on the presence or absence of cardiovascular disease risk factors and whether the exercise will be moderate or vigorous in intensity [50]. Subjects at low risk would be those who are young in age ( $<45$ years for male, $<55$ years for female), are asymptomatic, and have $\leq 1$ cardiovascular risk disease factors. These patients do not need a medical evaluation or stress test for moderate or even vigorous exercise. Subjects at moderate risk are older (men $>45$ years, women $>55$ years), or have $\geq 2$ risk factors for cardiovascular disease. For moderate exercise, no medical evaluation may be needed, but these subjects should undergo a stress test. If exercise of vigorous intensity is planned, both a medical evaluation and a stress test should be performed. For those patients at high risk, however, defined by $\geq 1$ sign or symptom of cardiovascular, pulmonary, or metabolic disease, both a full medical evaluation and stress test should be performed before any program is undertaken [50].

Specifically, those subjects who should not be exercising are those experiencing an acute myocardial infarction, subjects with unstable angina, systolic blood pressure $>180$, diastolic pressure $>110 \mathrm{ml} / \mathrm{Hg}$, uncontrolled diabetes mellitus, poorly controlled congestive heart failure, or thrombophlebitis [50].

\section{Conclusion}

While formal studies have shown that physician counseling is time-intensive and only minimally effective in changing behavior, physicians should no longer avoid the subject of recommendations for exercise as part of the healthcare they deliver to their patients. Physicians can begin by suggesting lifestyle changes such as climbing stairs at work, parking further away from the door on errands, walking regularly, and doing chores at home and in the yard. Clinicians should write on a prescription pad for the patient, specifying the type of exercise, duration, frequency, and intensity. The physician upon discharge from an office visit should determine plans for support and follow up to encourage success, manage 
obstacles, and prevent relapses. Clinicians should encourage their outpatients to involve community services such as physical therapy, mall-walking programs, school tracks, safe neighborhoods, the YMCA, and walk-a-thon's.

Physicians should counsel that exercise is not an option. The exercise does not have to be continuous to be effective, and any physical activity counts. Patients should sit less, stand more, and plan their exercise activity at the beginning of each week. Subjects should be encouraged to find activities which they enjoy and involve others to maintain compliance. As Edward Stanley, the Earl of Derby in 1873 said, "Those who think they have not time for bodily exercise will sooner or later have to find time for illness" [51].

\section{Compliance with Ethical Standards}

Conflict of Interest Keith R. Miller has received compensation from Nestlé for serving as faculty in its fellowship program, from Abbott for serving on a surgical advisory board, and from Metagenics for serving on an advisory board.

Stephen A. McClave declares that he has no conflict of interest.

Melina B. Jampolis declares that she has no conflict of interest.

Ryan T. Hurt has received compensation from Nestlé Nutrition for service as a consultant.

Kristine Krueger declares that she has no conflict of interest.

Sarah Landes declares that she has no conflict of interest.

Bryan Collier declares that he has no conflict of interest.

Human and Animal Rights and Informed Consent This article does not contain any studies with human or animal subjects performed by any of the authors.

\section{References}

Papers of particular interest, published recently, have been highlighted as:

- Of importance

1. Rezende LF, Rey Lopez JP, Matsudo VK, Luiz OD. Sedentary behavior and health outcomes among older adults: a systematic review. BMC Public Health. 2014;14(1):333.

2. $\quad$ www.cdc.gov/nchs/fastats/exercise.htm. Accessed June 12, 2016. Center for Disease Control and Prevention statistics regarding current levels of PA in the United States and trends in physican recommendations to patients relevant to exercise.

3. Lee IM, Djoussé L, Sesso HD, Wang L, Buring JE. Physical activity and weight gain prevention. JAMA. 2010;303(12):1173-9.

4. Warburton DE, Nicol CW, Bredin SS. Health benefits of physical activity: the evidence. CMAJ. 2006;174(6):801-9.

5. Garatachea N, Pareja-Galeano H, Sanchis-Gomar F, Santos-Lozano A, Fiuza-Luces C, Morán M, et al. Exercise attenuates the major hallmarks of aging. Rejuvenation Res. 2015;18(1):57-89. Discussion regarding the exercise mediated attenuation of physical fitness and functional decline in aging.
6. "Working With Special Populations Sport Essay." UKessays.com. 11 2013. All Answers Ltd. 062016 <https://www.ukessays. com/essays/sports/working-with-special-populations-sport-essay. php?cref $=1>$

7. Blumenthal JA, Babyak MA, Moore KA, Craighead WE, Herman $\mathrm{S}$, Khatri P, et al. Effects of exercise training on older patients with major depression. Arch Intern Med. 1999;159(19):2349-56.

8. Byrne A, Byrne DG. The effect of exercise on depression, anxiety and other mood states: a review. J Psychosom Res. 1993;37(6):565-74.

9. Macera CA, Hootman JM, Sniezek JE. Major public health benefits of physical activity. Arthritis Rheum. 2003;49(1):122-8.

10. Blair SN, Kohl 3rd HW, Paffenbarger Jr RS, Clark DG, Cooper KH, Gibbons LW. Physical fitness and all-cause mortality. A prospective study of healthy men and women. JAMA. 1989;262(17):2395-401.

11. Hu FB, Willett WC, Li T, Stampfer MJ, Colditz GA, Manson JE. Adiposity as compared with physical activity in predicting mortality among women. N Engl J Med. 2004;351(26):2694-703.

12. Taylor RS, Brown A, Ebrahim S, Jolliffe J, Noorani H, Rees K, et al. Exercise-based rehabilitation for patients with coronary heart disease: systematic review and meta-analysis of randomized controlled trials. Am J Med. 2004;116(10):682-92.

13. Hambrecht R, Niebauer J, Marburger C, Grunze M, Kälberer B, Hauer K, et al. Various intensities of leisure time physical activity in patients with coronary artery disease: effects on cardiorespiratory fitness and progression of coronary atherosclerotic lesions. J Am Coll Cardiol. 1993;22(2):468-77.

14. Sarzynski MA1, Burton J2, Rankinen T2, Blair SN3, Church TS2, Després JP4, et al. The effects of exercise on the lipoprotein subclass profile: a meta-analysis of 10 interventions. Atherosclerosis. 2015;243(2):364-72.

15. Hu FB, Stampfer MJ, Colditz GA, Ascherio A, Rexrode KM, Willett WC, et al. Physical activity and risk of stroke in women. JAMA. 2000;283(22):2961-7.

16. Helmrich SP, Ragland DR, Leung RW, Paffenbarger Jr RS. Physical activity and reduced occurrence of non-insulindependent diabetes mellitus. N Engl J Med. 1991;325(3): $147-52$.

17. Gregg EW, Gerzoff RB, Caspersen CJ, Williamson DF, Narayan KM. Relationship of walking to mortality among US adults with diabetes. Arch Intern Med. 2003;163(12):1440-7.

18. Boulé NG, Haddad E, Kenny GP, Wells GA, Sigal RJ. Effects of exercise on glycemic control and body mass in type 2 diabetes mellitus: a meta-analysis of controlled clinical trials. JAMA. 2001;286(10):1218-27.

19. Thune I, Furberg AS. Physical activity and cancer risk: dose-response and cancer, all sites and site-specific. Med Sci Sports Exerc. 2001;33(6 Suppl):S530-50. discussion S609-10.

20. Lee IM. Physical activity and cancer prevention-data from epidemiologic studies. Med Sci Sports Exerc. 2003;35(11):1823-7.

21. Holmes MD, Chen WY, Feskanich D, Kroenke CH, Colditz GA. Physical activity and survival after breast cancer diagnosis. JAMA. 2005;293(20):2479-86.

22. Wolff I, van Croonenborg JJ, Kemper HC, Kostense PJ, Twisk JW. The effect of exercise training programs on bone mass: a metaanalysis of published controlled trials in pre- and postmenopausal women. Osteoporos Int. 1999;9(1):1-12.

23. Kujala UM, Kaprio J, Kannus P, Sarna S, Koskenvuo M. Physical activity and osteoporotic hip fracture risk in men. Arch Intern Med. 2000;160(5):705-8.

24. Liu-Ambrose TY, Khan KM, Eng JJ, Heinonen A, McKay HA. Both resistance and agility training increase cortical bone density in 75- to 85-year-old women with low bone mass: a 6-month randomized controlled trial. J Clin Densitom. 2004;7(4):390-8. 
25. Feskanich D, Willett W, Colditz G. Walking and leisure-time activity and risk of hip fracture in postmenopausal women. JAMA. 2002;288(18):2300-6.

26. Ranjbar E, Memari AH, Hafizi S, Shayestehfar M, Mirfazeli FS. Eshghi MA. J Sports Med. 2015;6(2):e24055.

27. Cloud J. Why exercise won't make you thin. Time. 2009;174(6):49-51.

28. Swift DL, Johannsen NM, Lavie CJ, Earnest CP, Church TS. The role of exercise and physical activity in weight loss and maintenance. Prog Cardiovasc Dis. 2014;56(4):441-7.

29. Donnelly JE, Blair SN, Jakicic JM, Manore MM, Rankin JW, Smith BK. American College of Sports Medicine. American College of Sports Medicine Position Stand. Appropriate physical activity intervention strategies for weight loss and prevention of weight regain for adults. Med Sci Sports Exerc. 2009;41(2):459-71.

30. Church TS, Martin CK, Thompson AM, Earnest CP, Mikus CR, Blair SN. Changes in weight, waist circumference and compensatory responses with different doses of exercise among sedentary, overweight postmenopausal women. PLoS One. 2009;4(2):e4515.

31. Miller CT, Fraser SF, Levinger I, Straznicky NE, Dixon JB, Reynolds J, et al. The effects of exercise training in addition to energy restriction on functional capacities and body composition in obese adults during weight loss: a systematic review. PLoS One. 2013;8(11):e81692.

32. Hill JO, Thompson $\mathrm{H}$, Wyatt $\mathrm{H}$. Weight maintenance: what's missing? J Am Diet Assoc. 2005;105(5 Suppl 1):S63-6.

33. Steffens D, Maher CG, Pereira LS, Stevens ML, Oliveira VC, Chapple M, et al. Prevention of low back pain: a systematic review and meta-analysis. JAMA Intern Med. 2016;176(2):199-208.

34. Myers J, Kaykha A, George S, Abella J, Zaheer N, Lear S, et al. Fitness versus physical activity patterns in predicting mortality in men. Am J Med. 2004;117(12):912-8.

35. Warburton DE, Gledhill N, Quinney A. Musculoskeletal fitness and health. Can J Appl Physiol. 2001;26(2):217-37.

36. Buckley JP, Hedge A, Yates T, Copeland RJ, Loosemore M, Hamer $\mathrm{M}$, et al. The sedentary office: an expert statement on the growing case for change towards better health and productivity. Br J Sports Med. 2015;49(21):1357-62. Expert consensus on techniques to combat increased periods of sitting and inactivity in the modern workplace.

37. Tremblay MS, Esliger DW, Tremblay A, Colley R. Incidental movement, lifestyle-embedded activity and sleep: new frontiers in physical activity assessment. Can J Public Health. 2007;98 Suppl 2:S208-17.
38. McManus AM. Physical activity - a neat solution to an impending crisis. J Sports Sci Med. 2007;6(3):368-73.

39. Levine JA. Non-exercise activity thermogenesis (NEAT). Nutr Rev. 2004;62(7 Pt 2):S82-97.

40. Bouchard C, Tremblay A. Genetic influences on the response of body fat and fat distribution to positive and negative energy balances in human identical twins. J Nutr. 1997;127(5 Suppl):943S-7S.

41. Hill JO, Wyatt HR, Reed GW, Peters JC. Obesity and the environment: where do we go from here? Science. 2003;299(5608):853-5.

42. Campbell L, Wallman K, Green D. The effects of intermittent exercise on physiological outcomes in an obese population: continuous versus interval walking. J Sports Sci Med. 2010;9(1):24-30.

43. Fisher G, Brown AW, Bohan Brown MM, Alcorn A, Noles C, Winwood L, et al. High intensity interval- vs moderate intensitytraining for improving cardiometabolic health in overweight or obese males: a randomized controlled trial. PLoS One. 2015;10(10):e0138853.

44. Tudor-Locke C, Bassett Jr DR. How many steps/day are enough? Preliminary pedometer indices for public health. Sports Med. 2004;34(1):1-8.

45. Morris PE, Goad A, Thompson C, Taylor K, Harry B, Passmore L, et al. Early intensive care unit mobility therapy in the treatment of acute respiratory failure. Crit Care Med. 2008;36(8):2238-43.

46. Schweickert WD, Pohlman MC, Pohlman AS, Nigos C, Pawlik AJ, Esbrook CL, et al. Early physical and occupational therapy in mechanically ventilated, critically ill patients: a randomised controlled trial. Lancet. 2009;373(9678):1874-82.

47. Paffenbarger Jr RS, Hyde RT, Wing AL, Hsieh CC. Physical activity, all-cause mortality, and longevity of college alumni. $\mathrm{N}$ Engl J Med. 1986;314(10):605-13.

48. Lynch J, Helmrich SP, Lakka TA, Kaplan GA, Cohen RD, Salonen $\mathrm{R}$, et al. Moderately intense physical activities and high levels of cardiorespiratory fitness reduce the risk of non-insulin-dependent diabetes mellitus in middle-aged men. Arch Intern Med. 1996;156(12):1307-14.

49. U.S. Department of Health and Human Services. Healthy People 2010: Understanding and improving health. 2nd ed. Washington DC: US Government Printing Office; 2000.

50. Balady GJ, Weiner DA. Exercise testing for sports and the exercise prescription. Cardiol Clin. 1987;5(2):183-96.

51. http:/www.britannica.com/biography/Edward-Stanley-3rd-earl-ofDerby/article-supplemental-information.htm Accessed June 2016 